\title{
Estética e resistência em rede na cena do Teatro das Oprimidas
}

DOI: https://doi.org/10.22409/pragmatizes.v12i22.51149

\section{Marcos Horácio Gomes Dias ${ }^{1}$ Maria Bernardete Toneto ${ }^{2}$}

\begin{abstract}
Resumo: O objetivo deste artigo é contextualizar o surgimento do Teatro Madalena no debate sobre os direitos das mulheres e na cena artística brasileira Este artigo pretende entender como a luta pelo direito e pela a inclusão é possível por meio da arte, mesmo quando a realidade e os momentos são desfavoráveis. Serve também para pensarmos quais as escolhas que são feitas nesse projeto, quais propostas e os discursos que foram privilegiados.
\end{abstract}

Palavras-chave: teatro Madalena, mulher; gênero, Teatro do Oprimido, direitos civis, inclusão.

\section{Estética y resistencia en red en el Teatro das Oprimidas}

Resumen: El propósito de este artículo es contextualizar el surgimiento del Teatro Madalena en el debate sobre los derechos de las mujeres y en la escena artística brasileña. Este artículo pretende comprender cómo la lucha por los derechos y la inclusión es posible por medio del arte, incluso cuando la realidad y los momentos son desfavorables. También sirve para reflexionar sobre qué elecciones se hacen en este proyecto y cual propuestas y discursos se privilegiaron.

Palabras clave: Teatro Magdalena, mujer; teatro, derechos civiles, inclusión.

\section{Aesthetics and resistance in network in the scene of the Teatro das Oprimidas}

Abstract: The purpose of this article is to contextualize the emergence of Teatro Madalena in the debate on women's rights and in the Brazilian artistic scene. This article intends to understand how the struggle for rights and inclusion is possible through art, even when reality are unfavorable. It also serves to think about what choices are made in this project, what proposals and discourses were privileged.

Keywords: Madalena Theater, woman; gender, Theater of the Oppressed, civil rights, inclusion.

\footnotetext{
${ }^{1}$ Marcos Horário Gomes Dias. Doutor em História pela Pontifícia Universidade Católica de São Paulo, PUC/SP. Professor de pós-graduação e graduação no Centro Universitário Assunção (UNIFAl) e Universidade São Judas Tadeu (USJT) e no Museu de Arte Sacra de São Paulo (MAS), Brasil. Email: marcos.dias@saojudas.br - https://orcid.org/0000-0003-4815-8360

${ }^{2}$ Maria Bernardete Toneto. Doutoranda em Ciências, linha de pesquisa em Comunicação e Cultura, pelo Programa de Pós Graduação em Integração da América Latina, da Universidade de São Paulo (Prolam/USP), Brasil. E-mail: bernatoneto@gmail.com - https://orcid.org/0000-0002-7002-2534
} 


\section{Estética e resistência em rede na cena do Teatro das Oprimidas}

- Minha primeira pergunta, que por último enuncio, será: Ó maravilha! Sois humana ou divina? Que sois?

- Não maravilha, não divina, senhor; mulher, decerto. Diálogo entre Ferdinando e Miranda, em A Tempestade.

\section{Introdução}

O tema da participação das mulheres nas artes e na política permeia diversas discussões políticas, sociais e acadêmicas, assim como a ação de organizações e movimentos da sociedade civil, que em suas articulações incluem análises sobre questões de gênero, autodeterminação, dignidade e igualdade. Esse debate reitera práticas sociais e políticas que, além de preocupações individuais imediatas, enfocam a totalidade das condições sociais, em que a mudança fundamental da ordem social envolve as dimensões simbólicas e as relações delas decorrentes.

Formalmente, a discussão sobre a condição de subalternidade feminina cresceu na Europa e Estados Unidos a partir das lutas de emancipação das mulheres travadas a partir do século XIX. Mas esse movimento não é exclusivo dos países do Norte; em todo mundo o debate e as lutas conectam-se às realidades imediatas locais, à situação da mulher naquele espaço, aos direitos civis específicos e aos movimentos relacionados à liberdade de comportamento e expressão. Consequentemente, são diagnosticados conflitos entre os princípios que envolvem a luta por equidade para todas as pessoas, de todos os gêneros, e a realidade cotidiana concreta nos tempos e nos espaços geográficos onde elas vivem, sobrevivem e resistem. Neste jogo que envolve idealismo e práxis, não se trata apenas de formalmente postular igualdade entre mulheres e homens, até porque os sujeitos não são uniformes, dadas suas diferentes culturas e condições sociais. Esta conjuntura envolve contestar as condições concretas nas quais a promessa de igualdade não é realmente cumprida. 


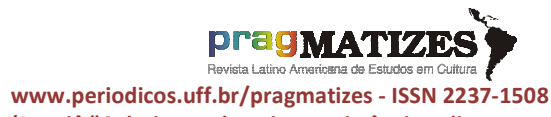

(Dossiê "Coletivos culturais - resistências, disputas e potências")
O processo da resistência das mulheres não ocorre em um cenário linear. Desenvolve-se em um palco em que acontecem encontros e confrontos entre tempo, espaço e condições. Neste jogo de cena, desde sempre é preciso considerar as condições concretas e simbólicas das mulheres, em especial as latino-americanas incluídas aí as brasileiras. Elas estão alijadas da política, ausentes em cargos de comando, subrepresentadas nas escolas e universidades, maioria entre os desempregados, exploradas como mão de obra barata, vítimas de estereótipos de gênero. Nas relações socioafetivas ainda são submetidas ao marido "chefe da família", socialmente definido como tal e detentor do autodireito de decidir sobre a rotina, a economia, a posse do corpo e da vida.

Como romper o silêncio imposto às mulheres? A ação da Rede $\mathrm{Ma}(\mathrm{g})$ dalena Internacional/Teatro das Oprimidas vai além do empoderamento do corpo e da voz pelas mulheres. "Provoca" os homens, e a própria sociedade, para não avançarem com a discriminação. Alerta que as próprias estruturas de representação social são reflexos de uma estrutura social dominada por homens. Nos laboratórios e em suas produções, desnudam as diversas formas de desigualdade institucionalizada. Divisão de trabalho, atribuição de papéis, padrões de representação, leis, monopólios de teoria e interpretação, papel sexual e heterossexismo são dimensões dessa desigualdade que são tematizadas de maneira constante pelos coletivos, de maneira provocativa ou mediadora; radical ou moderada. Para falar sobre as mulheres e as suas diversas condições, não basta repetir o velho: novas propostas estéticas precisam ser inventadas. O que há de novo nesse momento é a condição de rede que as Madalenas assumem, atingindo todos os continentes, em que o Brasil e América Latina têm muito a compartilhar.

\section{Teatro}

Em 1611, ao escrever e encenar a peça $A$ Tempestade, o dramaturgo inglês William Shakespeare inseriu apenas uma personagem feminina: Miranda. No drama, a ingênua filha de Próspero, mago e duque de Milão, é apresentada como uma jovem sem opinião, 
DIAS, Marcos Horácio Gomes; TONETO, Maria Bernadete. Estética e resistência em rede na cena do Teatro das Oprimidas. PragMATIZES -

Revista Latino-Americana de Estudos em Cultura, Niterói/RJ, Ano 12, n. 22, p. 191-218 mar. 2022.

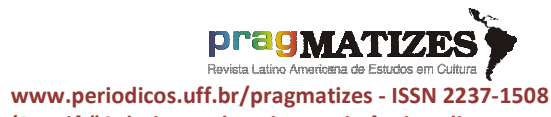

(Dossiê "Coletivos culturais - resistências, disputas e potências") submissa aos mandos masculinos. Enquanto o pai utiliza a magia para provocar uma tempestade e o consequente naufrágio do navio onde viajam seus inimigos, a jovem de 15 anos se vê envolvida em estratégias de conquista de poder, em um cenário povoado de seres etéreos.

Exilada em uma ilha com o pai por 12 anos, Miranda é desejada sexualmente por três personagens masculinos: o próprio pai, que pensa em violentá-la; Ferdinando, filho do rei de Nápoles e por quem se apaixona; e por Caliman, um ser disforme e selvagem, nascido na ilha, filho da finada bruxa Sycorax e escravizado por Próspero. Antes de ser violada pelo amado e futuro marido, ela confessa:

Não conheço ninguém do meu sexo, não me recordo de nenhum rosto de mulher a não ser o meu próprio ao espelho. Nunca vi ninguém que pudesse chamar de homem além de você, bom amigo, e do meu querido pai. Ignoro as feições das pessoas fora daqui. (SHAKESPEARE, 2014, p. 127).

Tomando a liberdade de reinterpretar o drama shakespeariano, é pertinente afirmar que o teatro traduz a realidade, no jogo cênico em que confluem vida e arte. Ou, como escreveu o teórico, dramaturgo e diretor teatral Augusto Boal em seu último artigo, publicado em 2009: "Teatro é a verdade escondida". Desnudar essa verdade é ato de resistência, assim como se afirmar mulher é movimento de rebeldia, como comprova a experiência revolucionária da Rede Ma(g)dalena Internacional/Teatro das Oprimidas.

Quatro séculos após a primeira encenação de $A$ Tempestade ao rei da Inglaterra, continuam atuais as práticas de violência que permeiam as relações de poder no processo de domínio não apenas territorial, mas cultural e simbólico. É revelador o fato de a personagem Miranda se reconhecer mulher, sem saber o que a diferencia dos homens. É mulher com nome, sobrenome, ascendência reconhecida, status econômico e social comprovado, detentora de letras que, mesmo com aversão, se permite tentar "ensinar" a Caliban as boas maneiras. Mas mulher sem voz, sem protagonismo, acessório do homem, objeto de intenção de violência masculina. Acima de tudo: mesmo se definindo como gênero feminino, não reconhece qualquer outra mulher, do passado e do presente, nesta mesma 
DIAS, Marcos Horácio Gomes; TONETO, Maria Bernadete. Estética e resistência em rede na cena do Teatro das Oprimidas. PragMATIZES Revista Latino-Americana de Estudos em Cultura, Niterói/RJ, Ano 12, n. 22, p. 191-218 mar. 2022.

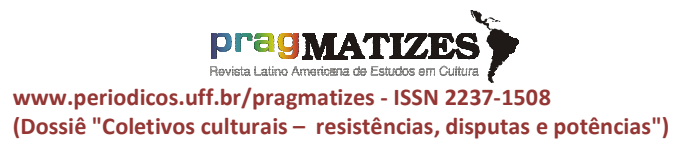

condição de subalternidade à autoridade masculina.

Pode-se considerar uma afronta relacionar o texto de Shakespeare ao processo de silenciamento das mulheres, o que, paradoxalmente, leva ao reconhecimento de um ser que tem corpo, expressão e voz, só que cerceados e calados. Neste contexto, Miranda representa a mulher que usa a voz para dizer o silêncio. De forma indireta, dá corpo à inexistência a ela imposta. Nesta trama, a protagonista contextualiza as invisíveis a quem não conhece. Faz um jogo revelador, mas subalterno, diferente das dinâmicas do Teatro das Oprimidas, que objetiva a resistência por meio do corpo, do gesto, da emoção, traçando a dança das existências femininas que são invisibilizadas.

A invisibilidade sistêmica não significa inexistência, muito pelo contrário. Basta ver que em resposta à exclusão que tem origem em práticas consolidadas por paradigmas masculinistas expressos em ações de dominação, as mulheres continuam se articulando de forma específica, transversal, horizontal e interseccionalmente ${ }^{3}$. Ocupam arenas a partir de ações multifacetadas e da valorização de práticas históricas de expressão, acolhimento e de partilha de conhecimentos. Neste sentido, por meio do corpo e da voz revela-se a importância da cultura do feminino como instrumento de reavaliação das contradições dos modelos de ser e estar no mundo, com impactos no reconhecimento da identidade do ser mulher.

A invisibilidade feminina é ontológica, no sentido de existir um consenso construído em torno de uma suposta inferioridade humana, expresso inclusive em não reconhecimento social. Afinal, os modelos de ser mulheres no mundo

\footnotetext{
${ }^{3}$ É usado o conceito de interseccionalidade desenvolvido pela francesa Silma Bilge, de uma "teoria transdisciplinar que visa apreender a complexidade das identidades e das desigualdades sociais por intermédio de um enfoque integrado. Ela [teoria] refuta o enclausuramento e a hierarquização dos grandes eixos da diferenciação social que são as categorias de sexo/gênero, classe, raça, etnicidade, idade, deficiência e orientação sexual. O enfoque interseccional vai além do simples reconhecimento da multiplicidade dos sistemas de opressão que opera a partir dessas categorias e postula sua interação na produção e na reprodução das desigualdades sociais" (BILGE, 2009, p. 70)
} 
DIAS, Marcos Horácio Gomes; TONETO, Maria Bernadete. Estética e resistência em rede na cena do Teatro das Oprimidas. PragMATIZES Revista Latino-Americana de Estudos em Cultura, Niterói/RJ, Ano 12, n. 22, p. 191-218 mar. 2022.

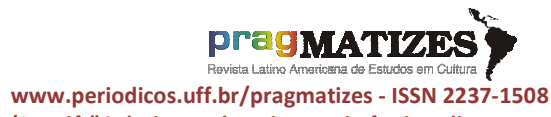

(Dossiê "Coletivos culturais - resistências, disputas e potências") não estão dados, e sim construídos na História ${ }^{4}$.

\section{Nascer e ser mulher}

Após a Revolução Francesa e a promulgação da Declaração dos Direitos dos Homens e dos Cidadãos (1789), as relações de gênero no mundo ocidental tornaramse cada vez mais um tema politicamente discutido. A ascensão das práticas do capitalismo moderno, novas formas para velhas práticas de exclusão e exploração, provocaram o surgimento do socialismo e diversas críticas à sociedade que nascia. As mulheres também faziam parte dessa mão de obra explorada pelo sistema industrial e enfrentavam a batalha da construção e da manutenção da família. Ganhavam menos que os homens e participavam de trabalhos pesados. O embrutecimento de pais e companheiros por esse mesmo sistema fazia com que sofressem amplamente na luta pela sobrevivência. Poderiam ser vitimadas

\footnotetext{
${ }^{4}$ Aqui se utiliza o plural "mulheres", elaborado por Mohanty (2008) em oposição ao conceito de "mulher". Conforme a autora, o segundo, no singular, refere-se ao "outro" ideológico e cultural, construído discursivamente, enquanto o primeiro, no plural, refere-se aos sujeitos reais.
}

no mundo familiar e no mundo do trabalho. A luta travada por vários setores sociais de então permitiram assim a criação de um vocabulário político que poderia ser usado também pelas mulheres como crítica à uma sociedade dominada pelos homens.

No século $X X$, após duas guerras mundiais, buscou-se a restauração de papéis de gênero rígidos e 0 modelo de casamento e família nuclear como o modo de vida padrão para que pudesse ocorrer uma suposta "normalização" das condições de vida. Embora as mulheres tivessem lidado com o mundo imediato por conta própria nas condições mais difíceis durante as guerras tiveram que lidar com a instrução clara para retornar ao lar e à família como o verdadeiro lugar e destino próprio à sua condição de gênero.

Em 1949, cenário da reconstrução política, econômica, social e cultural da Europa pós Segunda Guerra Mundial, a filósofa Simone de Beauvoir abre o segundo volume de sua obra mais famosa, 0 Segundo Sexo, com uma afirmação: "Não se nasce mulher, torna-se mulher". A constatação desnuda uma 
DIAS, Marcos Horácio Gomes; TONETO, Maria Bernadete. Estética e resistência em rede na cena do Teatro das Oprimidas. PragMATIZES Revista Latino-Americana de Estudos em Cultura, Niterói/RJ, Ano 12, n. 22, p. 191-218 mar. 2022.

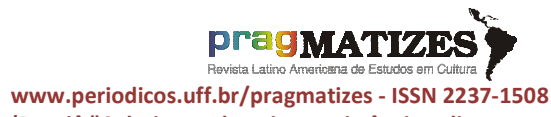

(Dossiê "Coletivos culturais - resistências, disputas e potências") realidade até a época pouco abordada: não se trata de nascer "menino" ou "menina", mas de assumir uma identidade que, historicamente, nega o determinismo de subalternidade de metade da população mundial. Também em $O$ segundo sexo, Beauvoir escreve: "Nunca se esqueça que basta uma crise política, econômica ou religiosa para que os direitos das mulheres sejam questionados. Esses direitos não são permanentes. Você terá que manter-se vigilante e atuante durante toda a sua vida" (BEAUVOIR, 2016, p.36).

No capítulo "Os mitos" de $O$ Segundo Sexo, Beauvoir argumenta que desde o começo do patriarcado os homens tiveram nas suas mãos "todos os poderes concretos; eles trabalharam também para manter as mulheres em estado de dependência; seus códigos estabeleceram-se contra ela; e assim foi que ela se constituiu concretamente como o outro".

\section{Um movimento para as mulheres}

A obra fundante do feminismo europeu pós-movimento sufragista do início do século $X X$ reconhece a fragilidade das mulheres na sociedade a partir da perspectiva da identidade feminina e dos direitos constituídos, tornando-se propulsora da teoria crítica feminista nos países centrais do capitalismo, onde a genealogia das demandas de gênero é registrada desde o final do século XIX.

Embora não haja consenso sobre a gênese do movimento feminino/feminista organizado, convenciona se que o final do século XIX é o período em que as questões de gênero, a luta pela equidade e a reflexão sobre o papel das mulheres passam a ganhar espaço na pauta política. A partir dessa época as postulações relacionadas aos direitos de mulheres começam a ocorrer de maneira mais estruturada, com a criação de entidades coletivas e o surgimento de demandas uniformes, bem como de esforços teóricos para dar sustentação às cobranças políticas relacionadas à sua situação social mulheres.

Aos ciclos de mobilização das mulheres, surgidos nos países do Norte ${ }^{5}$ convencionou-se chamar

\footnotetext{
${ }^{5}$ Utiliza-se aqui a divisão entre Norte e Sul em vez da classificação entre Primeiro e Terceiro Mundo. A opção baseia-se na atual divisão das ordens nacional e internacional provocada pelo processo de globalização neoliberal e os movimentos de posicionamento político e social para além da ideia civil global.
} 
DIAS, Marcos Horácio Gomes; TONETO, Maria Bernadete. Estética e resistência em rede na cena do Teatro das Oprimidas. PragMATIZES -

Revista Latino-Americana de Estudos em Cultura, Niterói/RJ, Ano 12, n. 22, p. 191-218 mar. 2022.

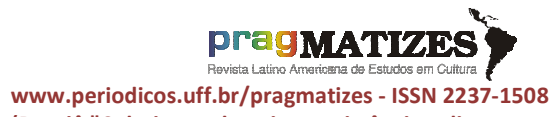

(Dossiê "Coletivos culturais - resistências, disputas e potências") "ondas

do

feminismo",

contextualizando

tempos

de

efervescência ativa e reflexiva em que questões específicas dominaram 0 debate social. A primeira onda data do final do século XIX. Alves e Pitanguy (1981) classificam esse ciclo como de ações contra o capitalismo estatal, marcado pelos movimentos sufragista e operário. Sob a inspiração da Revolução Francesa, em especial na França tem por fundamento a reivindicação de direitos a partir da discrepância entre os princípios universais de igualdade e a realidade de desigual divisão de poderes entre homens e mulheres.

Nos Estados Unidos e na Europa, a segunda onda se desenvolve nos anos 1960 a 1990. Detecta-se, nos países do Norte, três vertentes da segunda onda: a corrente igualitária, com foco na igualdade de direitos políticos, educacionais e na esfera do trabalho; a corrente radical, centrada na libertação da mulher da obrigatoriedade do papel e deveres biológicos e de subalternidade; e a corrente da feminitude, com foco nos problemas de ética e de identidade do sujeito feminino.
Fruto do pós-guerra, a segunda onda pode ser classificada como a do feminismo contra o capitalismo militarizado. Marcado pelo movimento da contracultura, baseia-se principalmente pela reivindicação por espaço na esfera pública, que gera um projeto intelectual e político para o pensamento e ação.

O movimento da contracultura foi um fenômeno cultural antissistema que se desenvolveu em grande parte do mundo ocidental entre meados da década de 1960 e meados da década de 1970. O movimento agregado ganhou ímpeto à medida que $\mathrm{O}$ Movimento dos Direitos Civis dos EUA continuava a crescer e, com a expansão da extensa intervenção militar do governo estadunidense no Vietnã. À medida que os anos 1960 avançavam, tensões sociais generalizadas também se desenvolveram em relação a outras questões, e tendiam a fluir ao longo das linhas geracionais em relação à sexualidade humana, aos direitos das mulheres, aos modos tradicionais de autoridade, experimentação com drogas psicoativas e diferentes interpretações do que seria a verdadeira realização pessoal. 
A afluência do pós-guerra permitiu que grande parte da geração da contracultura pensasse além das necessidades materiais da vida que preocuparam tantos seus pais nas eras anteriores. Esse momento gerou um número sem precedentes de jovens potencialmente insatisfeitos como possíveis participantes dessa sociedade e denunciavam 0 autoritarismo das "sociedades democráticas". Foram colocados em discussão processos de contracepção e a pílula, nudez pública, normalização do sexo antes do casamento, homossexualidade e legalização do aborto. Muitos movimentos importantes relacionados a essas questões nasceram e avançaram nas décadas seguintes.

A segunda onda do movimento de mulheres nos países centrais permitiu que se aprofundasse o debate sobre o papel das mulheres que, para além da biologia, tinham algo em comum, nomeadamente uma história violenta de danos e exclusão que as marginalizava, as definia como pessoas inferiores, excluídas da participação pública, e as expunha à violência cotidiana. Um grande catalisador para essas discussões foi justamente o já citado trabalho de Simone de Beauvoir. As suas perguntas ainda estavam pertinentes: O que é uma mulher? Por que a mulher é a outra?

A diferença entre os sexos, que ao mesmo tempo serve de justificativa para a opressão das mulheres, não é natural, mas cultural. A construção das mulheres como o sexo oposto só pode ser explicada a partir dos conceitos morais, normas e costumes predominantes de uma cultura. De acordo com essa concepção, não existe algo como "tipicamente masculino" ou "tipicamente feminino", mas apenas diferenças de comportamento entre os sexos baseadas na socialização específica de gênero e na divisão de tarefas. O objetivo dessa luta pela emancipação seria a abolição de todas as injustiças e diferenças sociais específicas de gênero, a fim de permitir que as pessoas vivessem de acordo com suas habilidades e preferências individuais, em vez de se adequarem à papéis de gênero socialmente prescritos. Em sua obra, Beauvoir exorta as mulheres a não se contentarem com sua condição de complemento do homem e a 
DIAS, Marcos Horácio Gomes; TONETO, Maria Bernadete. Estética e resistência em rede na cena do Teatro das Oprimidas. PragMATIZES -

Revista Latino-Americana de Estudos em Cultura, Niterói/RJ, Ano 12, n. 22, p. 191-218 mar. 2022.

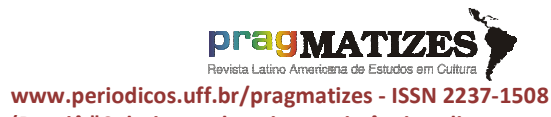

(Dossiê "Coletivos culturais - resistências, disputas e potências") reivindicarem sua igualdade na sociedade em todos os aspectos, ao mesmo tempo em que busca desmitificar a maternidade e defende o direito ao aborto.

Um livro da americana Betty Friedman, por sua vez, marca um novo debate nos movimentos internacionais. Friedman delineia uma análise crítica da sociedade norte-americana. Mostra que a publicidade, os meios de comunicação de massa e outras instituições de transmissão de ideologia trazem a ideia de uma existência plena como dona de casa e mãe. Por meio de inúmeras entrevistas, a pesquisadora mostra quão pouco essa ideologia correspondia à experiência real das mulheres.

Friedman viu a redução ao papel de donas de casa e mães como a causa do descontentamento e insatisfação de muitas das mulheres de classe média. Ela defende que uma mulher só poderia alcançar a si mesma se também considerasse suas próprias necessidades. Assim, encontra a chave central para a autoliberação no emprego das mulheres, embora isso não exclua o casamento e a maternidade.
Os debates ocorridos na segunda onda do movimento de mulheres levam literalmente à "redescoberta" de problemas como estupro, violência doméstica e abuso sexual. Coletivos e organizações de mulheres passam a discutir publicamente assuntos privados; mostram seus hematomas, cuidam das vítimas e nomeiam os perpetradores. Ativistas de vários grupos criam instalações de proteção, como chamadas de emergência, abrigos para mulheres e cursos de autodefesa.

Por outro lado, grupos progressistas e vinculados à transformação social continuam a ver a questão das mulheres como uma "contradição secundária". A luta primordial seria contra a desigualdade socioeconômica que geraria por si só as outras contradições. A principal questão a ser resolvida seria aquela entre trabalho assalariado e capital que, por consequência, resolveria e aboliria a opressão às mulheres, já que essas movimentações se estabeleceriam por si mesmas. Não valeria a pena fundar grupos específicos para discutir a questão feminina, mas sim recrutá-las para a 
DIAS, Marcos Horácio Gomes; TONETO, Maria Bernadete. Estética e resistência em rede na cena do Teatro das Oprimidas. PragMATIZES -

Revista Latino-Americana de Estudos em Cultura, Niterói/RJ, Ano 12, n. 22, p. 191-218 mar. 2022.

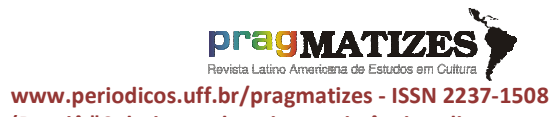

(Dossiê "Coletivos culturais - resistências, disputas e potências") luta maior contra os valores do capitalismo dominante.

Contra esse argumento levantase o exemplo do patriarcado como uma relação fundamental de exploração e opressão, visto que ocorre como uma constante em quase todas as formações sociais, inclusive as socialistas. Está, portanto, acima da contradição de classe. Essa discussão apela ao combate imediato contra o patriarcado, sem esperar por uma revolução socialista que não estivesse na ordem do dia. Nos debates culturais, analisa-se até os mitos antropológicos e religiosos que justificam a opressão das mulheres. A produção cultural também é atacada, revelando a humilhação e a submissão das mulheres com o seu erotismo patriarcal. Com esse último tópico surge assim o debate sobre a relação entre a sexualidade e a pornografia.

Imaginem. Como seria possível determinar a paternidade $\mathrm{e}$ manter o princípio de herança familiar, se a mulher resolvesse sair do controle masculino e se apoderar de seu corpo, de sua liberdade sexual e de expressão? Sair do "tal lugar de mulher"? Sair do lugar da culpa, da dívida, da mutilação, da burka? Sair da Eva e também da Cinderela, da Branca de Neve, da Barbie? (VANNUCCI, 2010, p. 108)
O mundo contemporâneo, já herdeiro das questões levantadas por essa história de luta e resistência, apresenta outro desafio. Com a ascensão do neoliberalismo, o processo de conscientização torna-se mais difícil pois, segundo alguns autores, o movimento das mulheres está caindo como uma marionete no modelo do novo capitalismo desregulamentado. Dentro do sistema neoliberal, os esforços do movimento das mulheres por mais participação no mercado de trabalho acabaram levando a um aumento das horas trabalhadas por família, juntamente com a queda simultânea nos salários e condições de trabalho precárias. Para muitos, as mulheres não foram integradas ao mercado de trabalho por razões emancipatórias, mas apenas para aumentar o crescimento econômico.

Essas estruturas hierárquicas e dogmáticas, dentro também dos próprios setores engajados, abafaram muitas vezes o potencial rebelde das questões femininas, como também as sufocaram. O movimento de mulheres e outros grupos que lutam por cidadania buscam então se reinventar e buscar caminhos onde poderiam 
DIAS, Marcos Horácio Gomes; TONETO, Maria Bernadete. Estética e resistência em rede na cena do Teatro das Oprimidas. PragMATIZES -

Revista Latino-Americana de Estudos em Cultura, Niterói/RJ, Ano 12, n. 22, p. 191-218 mar. 2022.

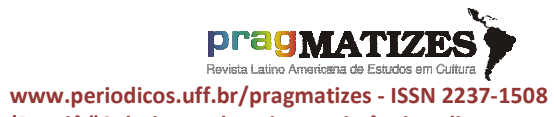

(Dossiê "Coletivos culturais - resistências, disputas e potências") contemplar suas próprias questões. A luta dessas mulheres passa a ser, além de convencer a população que seguia os padrões da sociedade dominante, o convencimento dos próprios grupos sociais engajados.

Esse é o cenário da terceira onda de organização das mulheres nos países centrais, nos anos 1990, que envolve a nova fase do capitalismo neoliberal relacionada ao processo de globalização do capital. É no seio da terceira onda que Butler, em 1990, desenvolve a teoria de gênero enquanto performance/performatividade (que rompe o paradigma da divisão entre natural e social, sexo e gênero).

Butler (2003) define a terceira onda como de reconhecimento de que as opressões atingem as mulheres de modos diferentes. Há a desconstrução da categoria "mulher" como um sujeito coletivo unificado que partilha as mesmas opressões, os mesmos problemas e a mesma história. Tratase de reivindicar a diferença dentro da diferença. Desse princípio surgem conceitos de redes e interseccionalidades do feminino com questões étnicas, sexuais, etárias e de renda.
O reconhecimento da diversidade aponta para especificidades das mulheres negras e indígenas e o racismo, da não imposição da heteroafetividade e a violência de identidade sexual e a exploração no trabalho que vitima operárias e trabalhadoras rurais, em oposição ao essencialismo e universalidade verificados até então. A reivindicação da diferença dentro da diferença também abre olhares para o outro, a outra distante, geográfica e culturalmente. As mulheres dos países centrais se veem diante de questões até então inexistentes para elas: o que a "diferente" tem a falar e que se deve ouvir? O que corpos distintos e suas expressões africanas, indígenas, latino-americanas têm a ensinar?

\section{A América Latina e a condição da mulher}

No caso da América Latina, a condição era - e é - muito mais difícil, baseada em extremos. As mulheres poderiam estar em grandes centros urbanos e fazer parte de uma rede de informações ocasionada, no mínimo, pelas precárias condições de trabalho e pela cultura de massa, ou poderiam estar ainda em situações rurais que 
DIAS, Marcos Horácio Gomes; TONETO, Maria Bernadete. Estética e resistência em rede na cena do Teatro das Oprimidas. PragMATIZES Revista Latino-Americana de Estudos em Cultura, Niterói/RJ, Ano 12, n. 22, p. 191-218 mar. 2022.

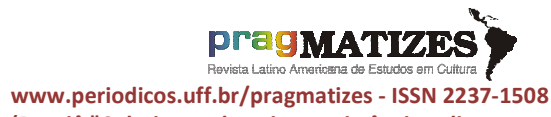

(Dossiê "Coletivos culturais - resistências, disputas e potências") lembravam os antigos padrões do período colonial ibérico. Situação essa muito semelhante às periferias das grandes cidades. Além de pensarem na situação da mulher no mundo, ainda tinham que superar condições não mais existentes em países da América do Norte ou da Europa ocidental.

Considera-se que no continente latino-americano, as ações das mulheres, para além de um sistema simbólico que reúne um conjunto de ações estruturadas e estruturantes de caráter de gênero/sexo, tem papel fundamental na desconstrução dos processos de exploração e dominação. Por suas características é uma categoria a ser inserida no movimento de decolonialidade do poder e da cultura, que conforme Aníbal Quijano (1997) pode se expressar em subversão radical e massiva, que conduz a uma revolução. ${ }^{6}$

\footnotetext{
${ }^{6}$ Quijano diferencia colonialidade de colonialismo. O segundo refere-se estritamente a uma estrutura de dominação/exploração em que o controle da autoridade política, dos recursos de produção e do trabalho de uma população determinada domina outra de diferente identidade e cujas sedes centrais estão, além disso, localizadas em outro local. Ou seja, o colonialismo revela uma relação política e econômica, na qual a soberania de um povo depende do poder de um outro povo ou nação. Já a colonialidade,
}

Quijano detecta que a
colonialidade do poder surge com a colonização, quando o homem branco questiona se os indígenas tinham ou não alma. O mesmo se aplica aos negros, mestiços, e de forma ainda mais acentuada às mulheres, desde sempre consideradas sujeitos inferiores e sem capacidade de pensamento e de expressão. Assim, elas são seres invisíveis em uma escala vertical de validação de uma suposta humanidade completa.

O aspecto relacional homem versus mulher que fundamenta a relação de gênero, cujo conceito nasce nos países ocidentais hegemônicos, não consegue abarcar a complexidade da América Latina, continente multirracial e pluricultural, em que a colonização impôs uma forma de distinção muito mais avançada - e cruel: a do humano versus o não humano. Não foi à toa que a colonização da América Latina e

que tem na América Latina um eixo central, implica relações racistas e androcêntricas de poder, sendo mais profunda e duradoura que o colonialismo. Sustenta-se na imposição de uma classificação, primordialmente racial e étnica da população, como pedra angular do referido padrão de poder e opera em cada um dos planos, meios e dimensões, materiais e subjetivos, da existência social cotidiana e de escala social. 
DIAS, Marcos Horácio Gomes; TONETO, Maria Bernadete. Estética e resistência em rede na cena do Teatro das Oprimidas. PragMATIZES Revista Latino-Americana de Estudos em Cultura, Niterói/RJ, Ano 12, n. 22, p. 191-218 mar. 2022.

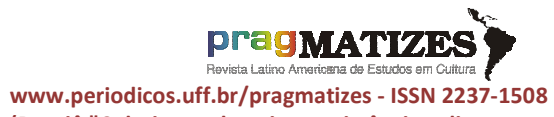

(Dossiê "Coletivos culturais - resistências, disputas e potências")
Caribe tentou negar o caráter humano do colonizado a serviço do homem ocidental, mesmo após a publicação da bula papal Sublimis Deo, emitida em 1537 pelo Papa Paulo III, que determinou que os indígenas são seres capazes de compreender a fé cristã, portanto humanos. A mesma lógica foi aplicada em outras distinções hierárquicas, entre elas as referentes a homens e mulheres, neste caso as mulheres brancas. Lugones (2014) exemplifica:

A "missão civilizadora" colonial era a máscara eufemística do acesso brutal aos corpos das pessoas através de uma exploração inimaginável de violações sexuais, do controle da reprodução e o terror sistemático (alimentando cachorros com pessoas vivas ou fazendo bolsas e chapéus das vaginas de mulheres indígenas brutalmente assassinadas, por exemplo). (LUGONES, 2014, p. 937)

A resistência das mulheres da América Latina, consideradas como não-seres humanos, percorreu caminho distinto daquele das mulheres dos países centrais. A gênese do movimento feminino/feminista latinoamericano teve a marca da luta pela igualdade política, expressa no direito ao voto. Foi organizada por mulheres das classes médias e altas, com preponderância de filhas de políticos e intelectuais que tiveram a chance de estudar em outros países. O posicionamento social gerou um caráter internacionalista do movimento, configurado na participação de encontros internacionais e culminando com a realização do Primeiro Congresso Feminino, em 1910, em Buenos Aires, e da $6^{\mathrm{a}}$ Conferência Internacional dos Estados Americanos, em 1928, em Havana, Cuba, em que foi criada a Comissão Interamericana da Mulher. Nesta fase não são consideradas as lutas das mulheres no cenário do fim da escravidão negra e das indígenas no mundo hispano-americano contra os latifundiários que começam a consolidar as formas de coronelismo.

$\mathrm{Na}$ segunda metade do século $X X$, a América Latina viveu a reação política conservadora das ditaduras militares que se instalaram em países "em desenvolvimento" e que entendiam qualquer forma de crítica ou contestação às normas sociais como rebeldia. Os regimes militares latinoamericanos são particularmente importantes para entender 0 desenvolvimento político do continente: são caracterizados pela 
DIAS, Marcos Horácio Gomes; TONETO, Maria Bernadete. Estética e resistência em rede na cena do Teatro das Oprimidas. PragMATIZES Revista Latino-Americana de Estudos em Cultura, Niterói/RJ, Ano 12, n. 22, p. 191-218 mar. 2022.

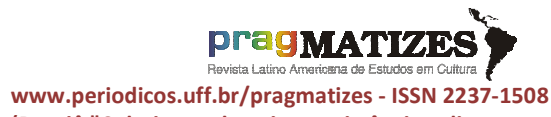

(Dossiê "Coletivos culturais - resistências, disputas e potências") repressão da oposição política por meio de medidas violentas como tortura, assassinatos e o "desaparecimento" de pessoas politicamente ativas. A legitimação do poder é propagada contra uma suposta ameaça ao Estado e à sociedade promovida pelos chamados grupos antissistema ou subversivos, que via de regra, mas não só, pertenceriam à luta política de esquerda. As ditaduras militares apareciam como supostas salvadoras do Estado, da economia e da cultura e promoviam um discurso de ordem e manutenção dos costumes sociais tradicionais. Não lidavam bem com a liberação dos costumes dos anos 1960 e dos debates teóricos promovidos pela contracultura. A nação deveria ser "reorganizada" de acordo com os ideais cristãos ultraconservadores e depois "devolvida" à democracia. Os elementos essenciais dessa visão de mundo estariam no tradicionalismo católico, na educação escolar baseada na autoridade, em valores norteamericanos e europeus de civilização (o que deixava exposto o racismo) e o anticomunismo.

Por conta disso, as mulheres latino-americanas não surfaram na segunda onda do feminismo central. Sua articulação esteve ligada à resistência às ditaduras, conforme Doris Lamus Canavae (2009):

O perfil organizacional nos anos 1970 a 1980 estava relacionado ao ambiente político que envolvia os movimentos sociais progressistas em um período de repressivos regimes militares (Argentina, Brasil, Chile, Peru e Uruguai) e as democracias formais restritas ou de autoritarismo civil que se estendiam pelo continente. Em tal contexto, não apenas desafiavam o patriarcado e seu modelo de dominação estatal militarista mas também denunciavam, junto com outras correntes da oposição, a opressão e a exploração econômica e política. (LAMUS CANAVAE, 2009, p. 99).

Nos anos 1970, destaca-se o papel de resistência política das mulheres aos regimes políticos da região, à clandestinidade da sociedade civil e aos condicionamentos da esquerda revolucionária a que elas estavam vinculadas. Mas há pouco registro, por exemplo, sobre o papel das indígenas e negras que assumiram todas as tarefas de suas comunidades depois que os homens se juntaram (ou foram obrigados a se juntar) à luta armada, sofrendo inclusive violência sexual de ambas as partes do conflito. 


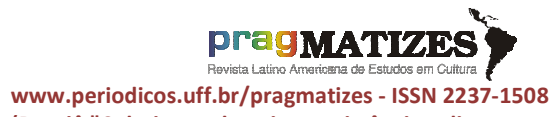

(Dossiê "Coletivos culturais - resistências, disputas e potências")
$\mathrm{Na}$ América Latina, a movimentação da resistência das mulheres, no que poderia ser classificado como "terceira onda", ganha fôlego no cenário de redemocratização das nações, da revisão do papel do Estado e das subsequentes crises fiscais, e sob impacto das consequências da implantação de projetos neoliberais. Essa linha do tempo estende-se até ascensão de governos progressistas liberais da América Latina nos primeiros anos do século XXI. Verificase uma ênfase sobre processos de institucionalização e discussão das diferenças intragênero.

Defrontando-se com novas maneiras de se organizar coletivamente, as mulheres passam por "novas" articulações de resistência. Alvarez (2003, p. 548) observa que, como resposta às dificuldades do contexto marcado pelo empobrecimento e violência, em contraste à face branca/mestiça e de classe média do movimento de mulheres nos seus primeiros tempos, nos anos 1980 floresce uma composição predominante de mulheres pobres, trabalhadoras, e/ou negras e indígenas. Ao mesmo tempo, despontam ações que levam em conta a complexidade da existência feminina, com a sensibilidade para as relações com o Cosmo, a terra, com os seres vivos e o inorgânico, entes cuja expressividade erótica, estética e linguística, cujos saberes, noções de espaço, expectativas, práticas, instituições e formas existir não eram para ser simplesmente substituídas, mas sim encontradas. Essas ações são sistematizadas em uma frase da artista aimará boliviana Julieta Paredes Carvajal: "Nós mulheres somos metade do todo":

Essas condições eram também compartilhadas por mulheres na África, Ásia, ou mesmo no leste da Europa que saía do socialismo. Essas mulheres precisavam ir além do debate dos grandes centros da democracia dos países ocidentais centrais e entender a sua realidade próxima de autoritarismo proclamado, censura, machismo tradicional e luta pela sobrevivência econômica. Como ex colonizadas, as ativistas pelos direitos das mulheres tiveram que incluir ainda o debate sobre 0 eurocentrismo que vinha sempre carregado de racismo e discriminação na produção intelectual desses 
centros. As necessidades específicas das mulheres das diferentes regiões culturais dos países periféricos não seriam consideradas se o discurso eurocêntrico continuasse monopolizando essa luta e essa fala.

Nos países periféricos ainda se luta por uma maior participação no mercado de trabalho e a tradição patriarcal barra ao máximo um movimento de autodeterminação sexual. Mesmo assim, os modelos e os projetos de vida das mulheres desses lugares também mudam $\mathrm{e}$ imagens tradicionais de feminilidade não combinam mais com aquilo que é almejado por elas. O reconhecimento conseguido com muitas dificuldades e o escândalo público da violência contra as mulheres promovem a consciência de alguns grupos deixando claras as relações estruturais de opressão dessas sociedades. Em nível internacional, o debate provindo das mulheres desses países começou a chamar a atenção. As mulheres do "terceiro mundo" começaram a criar muitas e diversas plataformas e iniciativas que estavam cada vez mais conectadas ao redor do globo e começavam a atrair a atenção mundial para o tema dos direitos femininos.

\section{Olhares culturais}

Pensar a resistência das mulheres sob a perspectiva cultural remete a um novo espelho, com imagem de complexa definição. Para além das conceituações, várias vertentes de pensamento convergem na dimensão societária da cultura, que não é apenas um significado produzido para ser decifrado como um "texto", mas sim um instrumento de intervenção no mundo e um dispositivo de poder.

Chauí (2014) lembra que, até antes mesmo do lluminismo as sociedades passaram a ser avaliadas segundo a presença ou não de alguns elementos, cuja ausência indicava ausência de cultura, introduzindo assim um conceito de valor para distinguir formas culturais, legitimando e justificando a colonização e o imperialismo. É preciso lembrar que, desde o início dos tempos, o ser humano se faz três perguntas fundamentais - De onde venho? Quem sou? Para onde vou? questões que articulam passado, presente e futuro, ou seja, sentidos da origem, da identidade e do destino, que demandam pensamento, 
DIAS, Marcos Horácio Gomes; TONETO, Maria Bernadete. Estética e resistência em rede na cena do Teatro das Oprimidas. PragMATIZES Revista Latino-Americana de Estudos em Cultura, Niterói/RJ, Ano 12, n. 22, p. 191-218 mar. 2022.

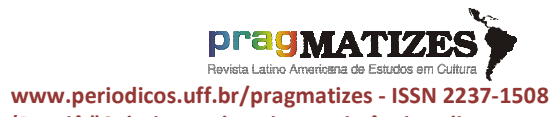

(Dossiê "Coletivos culturais - resistências, disputas e potências") sentimento, ato criativo e recriação da realidade concreta e simbólica.

A pergunta de fundo não está vinculada às diferenças em relação às mulheres de várias partes do mundo, mas sim às convergências no modo de ser, estar e viver. As mulheres latinoamericanas mostram isso por meio dos processos de viver e partilhar, valorizar o ser em lugar do possuir, a ideia de igualdade relacionada ao desenvolvimento do bem comum. Rompem, na prática, a ideia de que são limitadas por falta de conhecimento formal, teórico e acadêmico, desconsiderando assim o saber originado da práxis. Essa prática é expressa pelo corpo e pela voz em cena - no trabalho, nas ruas, nas organizações comunitárias, nos palcos.

É inconteste que, nos setores populares, bairros da periferia, no meio rural, na rua e no lar, negras, indígenas e brancas empobrecidas sempre estiveram vinculadas ao mundo do trabalho e à violência, fomentado pelos rescaldos das ditaduras, desaparecidos, militares e paramilitares, guerrilhas e mortes seletivas, fome, desemprego, desesperança. Mas é fundamental lembrar que a resistência criou redes de acolhimento e solidariedade, ações de partilha, produções culturais compartilhadas, busca do reconhecimento de saber e construção de uma cultura de paz.

Não se trata de carta de intenções. $\mathrm{Na}$ arte, vale o princípio defendido por Boal ao falar de teatro, em que interagem em condições de igualdade $\mathrm{o}$ ator e o espectador, considerado por ele como o grande ator social, pois tem o livre arbítrio em escolher o seu destino.

Essa é a fundamentação do Teatro do Oprimido ${ }^{7}$. Boal dá a deixa para a arte em cena das mulheres ao afirmar que, ao ver o mundo além das

\footnotetext{
${ }^{7}$ O Teatro do Oprimido começou a ser gestado após a prisão, tortura e expulsão de Augusto Boal pela ditadura militar brasileira, em 1971. Durante a primeira fase de exílio (1971-1976), em cinco países da América Latina (sequencialmente Argentina, Peru, Colômbia, Venezuela e Bolívia), e depois na França (1979-1986), Boal desenvolve experiências que combinam o fazer político com o fazer teatral, por meio de diversas técnicas teatrais. O objetivo do método é fazer o público (considerado ator) repensar a realidade e reformulá-la, uma vez que se conscientize que a sociedade está dividida entre opressores e oprimidos. Depois disso estará apto a assumir seu real papel, passando a ser sujeito da transformação social. Para que o processo se concretize, é proposto um novo conceito de autoria, em que o ator é destituído de seu papel de profissional de arte para a criação de um espaço de transformação comunitária e de escrita coletiva do mundo.
} 
DIAS, Marcos Horácio Gomes; TONETO, Maria Bernadete. Estética e resistência em rede na cena do Teatro das Oprimidas. PragMATIZES Revista Latino-Americana de Estudos em Cultura, Niterói/RJ, Ano 12, n. 22, p. 191-218 mar. 2022.

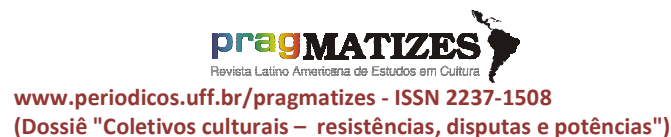

www.periodicos.uff.br/pragmatizes - ISSN 2237-1508 (Dossiê "Coletivos culturais - resistências, disputas e potências") aparências, vê-se opressores e oprimidos em todas as sociedades, etnias, gêneros, classes e castas, o mundo injusto e cruel. Assim surge a obrigação de inventar outro mundo pois outro mundo é possível, "mas cabe a nós construí-lo com nossas mãos entrando em cena, no palco e na vida" (BOAL, 2009).

\section{Palco da Vida}

Em seu último livro, $A$ estética do oprimido, editado e lançado postumamente, Augusto Boal sistematiza não apenas os princípios do Teatro do Oprimido, mas uma concepção de estética democrática e subjuntiva que, por meio da arte, permite a cidadão questionar dogmas e certezas, hábitos e costumes suportados na vida. Para isso, recorre ao exemplo da violência contra as mulheres:

Todo poder autoritário é violência. Aquela mulher indiana que disse "Meu marido não me bate mais do que o necessário, portanto não sou oprimida!" revela a existência de um poder marital que não é maior nem menor do que aquele que sofre aquela mulher nórdica que justificou seu esposo: "É verdade que, no meu país, pelo mesmo trabalho e mesmas condições, os homens ganham mais do que nós, mulheres. Mas isso não é opressão porque nossos homens são bons para nós!". Elas não percebiam que a violência do poder não está apenas no seu exercício - está na sua existência".

Como a violência pode se manifestar sem que seja exercitada? Pelo espetáculo, pela estética. Como se revela e pode ser combatida? Pela estética e pelo espetáculo, que se extrapolará para a realidade onde se torna real e nela se completa. Uma nova estética é urgente. A estética do oprimido é um ensaio de revolução" (BOAL, 2009, p. 158).

O palco - da arte e da vida - é onde acontecem os movimentos que transformam a realidade. É espaço de relações, de redes, compostas por nós e laços. É importante perceber que a ideia de rede é parte constitutiva da existência das latino-americanas. Redes de lutas, redes de resistência, redes de acolhimento, redes de convivência, redes de expressão, redes de sentimentos.

As potencialidades das articulações em rede estão presentes na Rede $\mathrm{Ma}(\mathrm{g})$ dalena Internacional (RedMa(g)dalena Internacional), composta por arte-ativistas e organizações feministas organizada em cinco regionais (América Central, México e Equador; América do Sul de fala hispânica; Brasil; África; e Europa). A partir da metodologia do 
DIAS, Marcos Horácio Gomes; TONETO, Maria Bernadete. Estética e resistência em rede na cena do Teatro das Oprimidas. PragMATIZES -

Revista Latino-Americana de Estudos em Cultura, Niterói/RJ, Ano 12, n. 22, p. 191-218 mar. 2022.

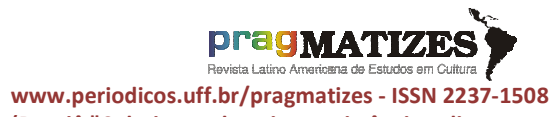

(Dossiê "Coletivos culturais - resistências, disputas e potências")
Teatro das Oprimidas $^{8}$, a rede desenvolve projetos teatrais de denúncia e de busca de estéticas feministas.

A rede é integrada por indígenas, afro-latinas, migrantes, imigrantes, lésbicas, não binárias, com diversidades funcionais e diferentes experiências em saúde mental, entre outros fatores que as classificam como "oprimidas" político-sociais. Como afirmam $\mathrm{m}$ manifesto da Rede $\mathrm{Ma}(\mathrm{g})$ dalena Internacional/Teatro das Oprimidas: "Somos oprimidas porque reconhecemos as opressões que vivemos e temos o desejo de mudálas. Nosso desejo e nossa necessidade são urgentes e é por meio de nossa criatividade teatral que encontramos caminhos para ser as protagonistas de nossas histórias".

Apesar da dimensão internacional das Madalenas e dos grupos que utilizam a metodologia do Teatro das Oprimidas, é fundamental ressaltar que foi no Brasil, e em seguida nos países latino-americanos e africanos, que surge a proposta de feminilizar as técnicas do Teatro do Oprimido. A primeira experiência ocorre em 2010 no Rio de Janeiro, liderado por Barbara Santos, dando origem à ação conjunta e em rede.

Em 2009, resolvemos fazer uma experiência de um laboratório só para mulheres, porque algumas discussões eram difíceis em grupos mistos. Tudo que tem a ver com sexualidade, medos, culpas, em grupo misto, fica nebuloso, porque a mulher logo sente que tem que se justificar. $A$ experiência foi fascinante. Fizemos o primeiro em janeiro de 2010. As mulheres que participaram começaram a trabalhar com outros grupos, e foi se multiplicando. Fiz laboratórios na Europa, na Índia. Na América Latina foi impressionante.

[...] Acho que a única explicação é a necessidade. O que faz uma coisa avançar não é que seja original. $O$ importante é que chegue na pessoa certa e as pessoas se apropriam disso. (SANTOS, 2016)

\section{Embora a concepção e} pesquisa estética se baseie no método teatral de diálogo desenvolvido por Boal, o Teatro das Oprimidas recusa o rótulo de "feminino plural" do projeto boaliano. E, se por um lado a Rede $\mathrm{Ma}(\mathrm{g})$ dalena Internacional/Teatro das Oprimidas baseia sua ação na sororidade, reconhecendo a universalidade da opressão e a especificação das realidades locais, por outro ressalta questões que devem particulares da realidade latino- 
DIAS, Marcos Horácio Gomes; TONETO, Maria Bernadete. Estética e resistência em rede na cena do Teatro das Oprimidas. PragMATIZES Revista Latino-Americana de Estudos em Cultura, Niterói/RJ, Ano 12, n. 22, p. 191-218 mar. 2022.

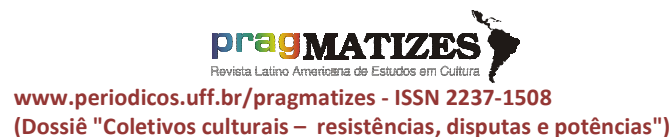

racismo, sem machismo, sem homofobia, sem lesbofobia, sem estereótipos ou mandatos sociais. Uma sociedade sem patriarcas, na qual seja possível reinventar e multiplicar os espaços de poder e diversificar quem os ocupa. (Primeiro Manifesto da Rede $\mathrm{Ma}(\mathrm{g})$ dalena Internacional, 2016, p. 13)

Cada coletivo individualmente e em rede pensa a conscientização por meio de produções artísticas que são resultantes desses encontros sistemáticos como peças de teatro, performances, instalações, a utilização de pinturas e esculturas; a expressão por meio de poesias e músicas, além da promoção de discussão e debates em torno desses eventos. A produção estética seria o processo pelo qual ocorre a conscientização e o empoderamento das mulheres.

A estratégia é trazer a percepção que as mulheres podem aumentar seu grau de autonomia e autodeterminação e capacitá-las para que sejam agente transformador de sua realidade imediata, de sua família e de sua comunidade. O objetivo é promover uma sensibilização adequada que gere uma cultura de confiança e a capacitação para assumir responsabilidades ditas "não femininas". O protesto é dirigido 
DIAS, Marcos Horácio Gomes; TONETO, Maria Bernadete. Estética e resistência em rede na cena do Teatro das Oprimidas. PragMATIZES Revista Latino-Americana de Estudos em Cultura, Niterói/RJ, Ano 12, n. 22, p. 191-218 mar. 2022.

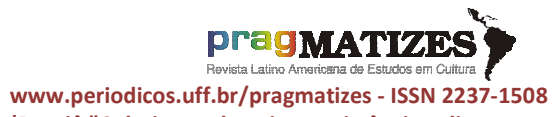

(Dossiê "Coletivos culturais - resistências, disputas e potências") principalmente contra a imagem comercializada e estereotipada do corpo feminino idealizado, principalmente no mundo da moda, contra a homofobia contínua na sociedade (no caso das lésbicas), contra o racismo e contra as oportunidades educacionais desiguais. Em relação ao racismo, estrutural no Brasil e em outros países latinoamericano, podemos pensar:

[...] a. resgatar os valores da cultura africana, marginalizados por preconceito à mera condição folclórica, pitoresca ou insignificante; $b$. Através de uma pedagogia estruturada no trabalho de arte e cultura, tentar educar a classe dominante "branca", recuperando-a da perversão etnocentrista de se autoconsiderar superiormente europeia, cristã, branca, latina e ocidental; c. Erradicar dos palcos brasileiros $\mathrm{O}$ ator branco maquilado de preto, norma tradicional quando a personagem negra exigia qualidade dramática do intérprete; [...] (NASCIMENTO, 2016, p. 161)

Busca-se assim uma série de conhecimentos culturais de raízes não europeias que resgatam estruturas espirituais, esotéricas ou não cristãs que foram e são moldadas pelo feminino e por tradições matriarcais. Lembram constantemente dos arquétipos da "grande deusa" em suas três formas: menina, mãe e a sábia anciã. A histórica caça às bruxas é metaforicamente interpretada como a lembrança de uma tentativa de destruição do conhecimento feminino sobre o mundo.

O encontro de mulheres é usado como um momento gerador de autorresponsabilidade e autodeterminação. A luta é não deixar que o conhecimento morra ou resgatar aquele que já foi perdido. Por isso, acoplada a essa percepção, está a necessidade e a percepção da alteridade do feminino, que é pelo menos igual, senão superior ao masculino (pensamento da diferença). A abordagem parte de uma intervenção orientada em biografias, autobiografias, narrativas e histórias de vida. O empoderamento é um conceito central na promoção da saúde mental e corporal das participantes e se refere ao processo de emancipação frente aos valores patriarcais, à busca profissional, a percepção da falta de influência nas decisões da sociedade e, por consequência, sua sub-representação sociopolítica. O trabalho pensa no contexto de uma formação política e democrática e essas atividades são 
DIAS, Marcos Horácio Gomes; TONETO, Maria Bernadete. Estética e resistência em rede na cena do Teatro das Oprimidas. PragMATIZES Revista Latino-Americana de Estudos em Cultura, Niterói/RJ, Ano 12, n. 22, p. 191-218 mar. 2022.

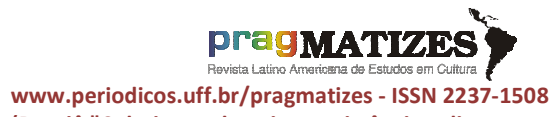

(Dossiê "Coletivos culturais - resistências, disputas e potências") entendidas como instrumentos para aumentar a cidadania.

A proposta estética do Teatro das Oprimidas desenvolvida pelos coletivos da Rede $\mathrm{Ma}(\mathrm{g})$ dalena defende uma estrutura social no qual a opressão às mulheres seja eliminada como norma social. As Madalenas consideram as ordens sociais prevalecentes como androcêntricas e interpretam esta circunstância como estrutural e como resultado de uma dominação patriarcal gerada há séculos. Suas intervenções abrem espaço para que os homens não tenham sua autoimagem vinculada à dominação sobre as mulheres. Esta afirmação vai ao encontro e faz coro às propostas de vários grupos atuais que defendem que a própria visão do mundo que temos e o conhecimento construído pela humanidade estão baseados em um olhar masculino e que as mulheres precisam ocupar esse espaço, mostrando uma observação feminina do vivido. A sociedade teria como tarefa tornar visíveis as conquistas das mulheres e revelar as omissões anteriores sobre a história feminina. A pesquisa desse grupo fala, além de tudo, sobre tornar visível o trabalho privado feminino que fora sempre invisível. Essa feminilidade do conhecimento pode, nesse sentido, compreender também o mundo intuitivo, o esotérico e o pensamento não racional que são considerados alijados do ponto-devista masculino.

\section{Reflexões finais}

A Rede Ma(g)dalena Internacional/Teatro das Oprimidas busca a implementação dos princípios sociais básicos modernos que têm se espalhado enquanto ideal desde a Revolução Francesa, da modernização econômica e da proclamação dos Direitos Humanos. Uma luta que vai além do solo europeu ou estadunidense. Trata-se do princípio básico do reconhecimento de sua igual dignidade humana por meio do qual os princípios fundamentais de liberdade e igualdade para todas as pessoas traz, objetivamente, o reconhecimento para as mulheres. Essa busca permite um debate aberto sobre a igualdade política e jurídica, a educação, a autodeterminação sexual, os direitos humanos para mulheres e a emancipação de currículos prescritos e modelos de comportamento tradicional. 
A invocação da dignidade humana provoca uma remoção de costumes arraigados e construídos pelas ordens sociais de gênero assimétricas, nas quais a dignidade é um conceito definido por gênero. Com base nos costumes tradicionais, a dignidade dos homens é considerada "honrosa" e a dignidade das mulheres como "modéstia". Na vida cotidiana, o comportamento é então classificado como digno ou indigno com a ajuda de estereótipos de papéis "gênero avaliativos". Se, por outro lado, a dignidade humana é considerada inviolável, independentemente do sexo, não há justificativa para violar a dignidade das mulheres. O princípio básico da dignidade humana promove uma melhor observância dos direitos fundamentais à liberdade e à igualdade.

Esse debate abraça temas como os direitos civis de afroamericanos e afro-europeus, populações indígenas, diferentes cores de pele ou de origem ocidental e não ocidental, situações de pobreza ou a luta pela independência dos corpos e das mentes nas áreas que foram colonizadas pelos europeus. Além de sua condição de mulher, sua situação econômica, étnica e cultural pode estar ligada a alguma dessas realidades, o que dificulta sua percepção, sua luta e sua realização como pessoa.

Como uma rede de discussão feminina espalhada por diversos países e continentes, o Teatro das Madalenas se percebe trabalhando bastante com a internet e atuando de forma on-line, de uma maneira orientada a objetivos em projetos interseccionais, debatendo constantemente o machismo e a heteronormatividade. Esse debate interseccional se desenvolve principalmente a partir das críticas de mulheres negras e indígenas no Brasil, África e Europa que observam o racismo na sociedade onde vivem e também no próprio movimento atuante de mulheres. Suas bases incluem plataformas a partir da visão de um mundo decolonial que se une a uma rede de mulheres de países não centrais. O que se pretende é uma rede intencional de parcerias e a identificação de uma luta em comum, mesmo em situações geográficas dispersas e afastadas. Todas as envolvidas, além de sua condição feminina, trazem como registro as cicatrizes da colonização de seus 
DIAS, Marcos Horácio Gomes; TONETO, Maria Bernadete. Estética e resistência em rede na cena do Teatro das Oprimidas. PragMATIZES Revista Latino-Americana de Estudos em Cultura, Niterói/RJ, Ano 12, n. 22, p. 191-218 mar. 2022.

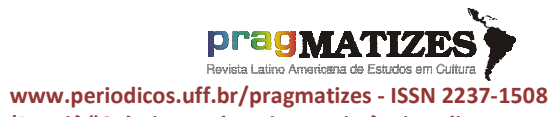

(Dossiê "Coletivos culturais - resistências, disputas e potências") povos. Nesse sentido, lutam de uma forma diferenciada em comparação às mulheres europeias ou estadunidenses.

Mesmo assim, sua rede também está instalada em países desenvolvidos. Essa situação faz com que percebamos que não estamos falando apenas das periferias do mundo, mas também das periferias dos grandes centros, das cidades enriquecidas e dos países com alta qualidade de vida. Nesses espaços encontramos refugiados, imigrantes, migrantes, trabalhadores de baixa renda, violência doméstica e, sobretudo, mulheres que formam uma parte significativa de todo esse caleidoscópio. Elas, em cena e em rede, podem e estão presentes em todos esses lugares.

A questão central indiscutível de toda essa produção é a desigualdade nos campos da participação política, econômica e intelectual, bem como a crítica à violência. As mulheres envolvidas nesse projeto consideram ser capazes de levar uma vida autodeterminada sem violência, com a condição e a possibilidade de uma real existência de liberdade e igualdade. Criticam a falta de valorização da subjetividade feminina, que se expressa na desvalorização dos corpos e mentes. Desnudam sobretudo o modelo de individualidade universal, supostamente neutra em termos de gênero. Algumas lembram que a mulher incorpora uma moralidade diferente do homem por causa da experiência da maternidade e da experiência feminina do cuidado. A partir dessa vivência estética, examina-se a construção do termo "gênero" nos diversos contextos, seu significado e seus efeitos na distribuição do poder político, nas estruturas sociais e na produção de conhecimento, da cultura e da arte. O aumento da consciência dessas mulheres seria explorar os aspectos políticos de sua própria vida pessoal.

\section{Referências bibliográficas}

ALVES, Branca Moreira; PITANGUY, Jacqueline. $O$ que é feminismo. [Coleção Primeiros Passos]. São Paulo: Brasiliense, 1981.

BALLESTRIN, Luciana. Feminismos Subalternos. Revista Estudos Feministas, Florianópolis, v. 25, n. 3, p. 1035-1054, 2017.

BALLESTRIN, Luciana. Feminismo De(s)colonial como Feminismo Subalterno Latino-Americano. Revista Estudos Feministas, Florianópolis, v. 28, n. 3, e75304, 2020. Disponível em: http://www.scielo.br/scielo.php?script= 
DIAS, Marcos Horácio Gomes; TONETO, Maria Bernadete. Estética e resistência em rede na cena do Teatro das Oprimidas. PragMATIZES Revista Latino-Americana de Estudos em Cultura, Niterói/RJ, Ano 12, n. 22, p. 191-218 mar. 2022.

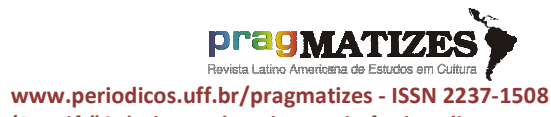

(Dossiê "Coletivos culturais - resistências, disputas e potências") sci arttext\&pid=S0104-

$02 \overline{6} \times 2020000300200 \&$ lng $=$ pt\&nrm=iso

. Acesso em: 25 jul. 2021.

BEAUVOIR, Simone. O segundo sexo: Fatos e Mitos. Rio de Janeiro: Nova Fronteira, 1980.

BILGE, Sirma. Théorisations féministes de l'intersectionnalité. Paris: Diogène, 2009.

BOAL, Augusto. A estética do oprimido. Rio de Janeiro: Garamond, 2009a.

BOAL, Augusto. Jogos para atores e não atores. Rio de Janeiro: Civilização Brasileira, 2007.

BOAL, Augusto. O arco-íris do desejo: método Boal de teatro e terapia. Rio de Janeiro: Civilização Brasileira, 2002.

BOAL, Augusto. O teatro como arte marcial. Rio de Janeiro: Garamond, 2009b.

BOAL, Augusto. O Teatro do Oprimido $e$ outras poéticas políticas. Rio de Janeiro: Civilização Brasileira, 2005.

BOURDIEU, Pierre. Questões de Sociologia. Rio de Janeiro: Marco Zero, 1983.

BOURDIEU, Pierre. Sociologia. [org.: Renato Ortiz]. São Paulo: Ática, 1983.

BUTLER, Judith P. Problemas de gênero: Feminismo e subversão da identidade. Rio de Janeiro: Civilização Brasileira, 2003.

CHAUIÍ, Marilena. Cultura e democracia. O discurso competente e outras falas. São Paulo: Cortez, 2009.

CHIARI, Gabriela Serpa. Laboratório Madalena: Inovação pedagógica para o gênero feminino. Universidade Federal do Estado do Rio de Janeiro/UNIRIO, 2013.
COUTO, Mia. E se Obama fosse africano? Ensaios. Lisboa: Ed. Caminho, 2009. Disponível em http://pt.calameo.com/read/002023023 4ec7bf740203. Acesso em: 21 jul. 2013.

CRUZ, Carmen de la. Guia metodológica para integrar la perspectiva de gênero enproyectos y programas de desarrollo. Emakunde. Instituto Vasco de La Mujer. Vitoria Gasteiz, dezembro, 1998. Disponível em:

http://www.emakunde.euskadi.net/cont enidos/informacion/pub_guias/es_ema kunde/adj untos/guia_genero_es.pdf. Acesso em: 19 jul. 2021

DESGRANGES, Flávio. A pedagogia do teatro. provocação e dialogismos. São Paulo: Hucitec, 2006.

DUARTE, Constância Lima. Feminismo e literatura no Brasil. Estudos avançados, vol. 17, n. 49, dez. 2003. Disponível em: http://www.scielo.br/scielo.php?pid=S0 103-

40142003000300010\&script=sci_arttex t. Acesso em: 19 jul. 2021

FERNANDES, Sílvia. Teatralidades contemporâneas. São Paulo: Perspectiva, 2010.

FIORATTI, Gustavo. Teatro do oprimido atrai mulheres no Oriente. Folha de São Paulo, 13/11/2012. Disponível em: http://www1.folha.uol.com.br/ilustrada/ 1184289- teatro-do-oprimido-atraimulheres-muculmanas-nooriente.shtml. Acesso em: 21jul.2021.

FREIRE, Paulo. A importância do ato de ler: Em três artigos que se completam. [Coleção Polêmicas de Nosso Tempo, vol. 4]. São Paulo: Autores Associados/ Cortez, 1989. 
DIAS, Marcos Horácio Gomes; TONETO, Maria Bernadete. Estética e resistência em rede na cena do Teatro das Oprimidas. PragMATIZES Revista Latino-Americana de Estudos em Cultura, Niterói/RJ, Ano 12, n. 22, p. 191-218 mar. 2022.

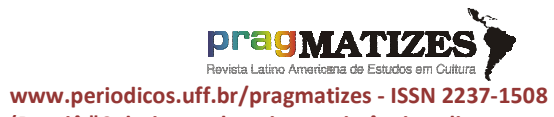

(Dossiê "Coletivos culturais - resistências, disputas e potências")
FREIRE, Paulo. Pedagogia do Oprimido. Rio de Janeiro: Paz e Terra, 2016.

GANGYLY, Sanjoy. Aprendendo com as pessoas. Metaxis: a revista do Teatro do Oprimido, Rio de Janeiro, Teatro do Oprimido de ponto a ponto, $\mathrm{n}^{\circ} 6, \mathrm{p} .18-22,2010$.

GARCIA, Carla Cristina. Breve história do feminismo. São Paulo: Editora Claridade, 2011.

ICLE, Gilberto. Pedagogia teatral como cuidado de si. São Paulo: Hucitec, 2010.

LAMUS CANAVAE, Doris. Localización geohistórica de los feminismos latino americanos. Polis Revista de la Universidad Bolivariana, vol. 8, n. 24, p. 95-109, 2009.

LUGONES, Maria. Colonialidade e gênero. In: BUARQUE DE HOLLANDA, Heloísa (org.). Pensamento feminista hoje: perspectivas decoloniais. Rio de Janeiro: Bazar do Tempo, 2020.

LUGONES, Maria. Rumo a um feminismo descolonial. Hypatia, v. 25, n. 4, 2010.

MOHANTY, Chandra Talpade. Bajo los ojos del Occidente: academia feminista y discursos coloniales. In: NAVAZ, Lilian Suárez; HERNANDEZ, Rosalva Aída (eds.). Descolonizando el feminismo - teorias y practicas desde los márgenes. [Instituto de La Mujer] Valencia: Ediciones Cátedra, 2008.

MURGUIALDAY, Clara. Genero. In: Diccionario de acción humanitária y cooperación al desarrollo. [Bilbao]: Hegoa, c2005.

NASCIMENTO, Abdias do. O genocídio do negro brasileiro: processos de um racismo mascarado. São Paulo: Perspectivas, 2016.

NASCIMENTO, Abdias do. Teatro Experimental do Negro: trajetória e reflexões. Estudos Avançados. 2004.

PRIORE, Mary Del. Ser bela e sedutora no passado. Ciclo de Palestras Um Olhar sobre o Feminino. Itaú Cultural. www.itaucultural.org.br/.educação/dow nload/Mary.doc . Acesso em: 5 jul. 2021.

QUIJANO, Aníbal. Colonialidaddel poder, cultura y conocimiento en América Latina. Anuario Mariateguiano, Lima, vol. IX, n. 9, 1997.

QUIJANO, Aníbal. Colonialidaddel poder. cultura, y conocimiento en América Latina. Ecuador Debate, $\mathrm{n}$. 44, p. 227-238, ago. 1998.

QUIJANO, Aníbal. Colonialidade de poder: Eurocentrismo e América Latina. In: Colonialidade do saber: eurocentrismo e ciências sociais: perspectivas latino americanas. Buenos Aires: Clacso, 2005.

QUIJANO, Aníbal. Cuestiones $y$ horizontes: de la dependencia histórico-estructural a la colonialidad/descolonialidad del poder. Buenos Aires: Clacso, 2014.

RED MA(G)DALENA INTERNACIONAL (Diversos Países). RedMa(g)dalena Internacional. 2016. Disponível em: https://teatrodelasoprimidas.org/redmagdalena/ Acesso em: 30 jul. 2021.

RODRIGUES, Almira. Mulheres, femininos e feminismos: construindo igualdades e afirmando diferenças. Disponível

em: http://www.cfemea.org.br/index.php?op tion=com_content\&view=article\&id=15 
73:mulhe res-femininos-e-feminismosconstruindo-igualdades-e-

afirmandodiferencas\&catid=212: artigos -e-textos\&Itemid=146. Acesso em: 21 jul. 2021.

SANCTUM, Flávio. A estética de Boal: odisseia pelos sentidos. Rio de Janeiro: Multifoco, 2012.

SANTOS, B.; VANNUCCI, A. Madalena. O Teatro das Oprimidas. Metaxis:a revista do Teatro do Oprimido. Teatro do Oprimido de ponto a ponto, Rio de Janeiro, $\mathrm{n}^{\circ} 6, \mathrm{p} 101$ 103, 2010.

SARAPECK, Helen. É Brasil adentro, é mundo afora! Metaxis: a revista do Teatro do Oprimido. Teatro do Oprimido de ponto a ponto, Rio de Janeiro, n6, p. 34 - 37, 2010.

SARTI, Cynthia Andersen. O feminismo brasileiro desde os anos 1970: revisitando uma trajetória. Estudos Feministas. Florianópolis, v. 12, n. 2, p. 35-50, maio/ago. 2004.

SCOTT, Joan Wallach. Género e História. México: FCE, Universidad Autónoma de la Ciudad de México, 2008.

SHAKESPEARE, William. A tempestade. [tradução Rafael Raffaelli].Florianópolis: Editora UFSC, 2014.

SPIVAK, Gayatri Chakravorty. Pode o subalterno falar? Belo Horizonte: Editora da UFMG, 2010.

VANNUCCI, Alessandra. Lugar de Madalena. Metaxis:a revista do Teatro do Oprimido., Teatro do Oprimido de ponto a ponto, Rio de Janeiro, $\mathrm{n}^{\circ} 6, \mathrm{p}$. $108-110,2010$. 